\title{
Nucleosome Binding Domain
}

National Cancer Institute

\section{Source}

National Cancer Institute. Nucleosome Binding Domain. NCI Thesaurus. Code C13745.

The Nucleosomal Binding Domain anchors HMG-14 and HMG-17, two canonical HMG proteins, to nucleosomes. HMG-14 and HMG-17 are the only nuclear proteins known to specifically recognize the genetic structure of the 146-bp nucleosome, i.e., the building block of the chromatin fiber. Although the target of HMG-14/-17 is the nucleosome, the main function of these proteins is to change the architecture of the higher-order chromatin structure. These changes are mediated through the C-terminal region of the proteins. The nucleosomal binding domain anchors these HMG proteins to the nucleosome cores to facilitate HMG-14/-17-dependent changes in chromatin structure. 